\title{
Avaliações de impactos da urbanização de pequenas bacias nas vazões de base do rio: o caso das bacias do ribeirão Jardim e do córrego da Cachoeira
}

\section{Addressing the impacts of small watershed urbanization over river baseflows: the case of Jardim stream and Cachoeira creek's watersheds}

Data de entrada: $28 / 08 / 2017$

Data de aprovação: $14 / 09 / 2017$

\section{Resumo}

Este estudo apresenta o comportamento da vazão superficial de duas pequenas bacias para a previsão de impactos de um cenário de urbanização da bacia do ribeirão Jardim, o qual reflete a ocupação da bacia do córrego Cachoeira no presente. $O$ estudo é realizado em duas bacias localizadas entre Valinhos e Vinhedo, SP, sendo a do ribeirão Jardim produtora de água $\left(23,5 \mathrm{~km}^{2}\right)$ e a do córrego da Cachoeira urbanizada $\left(15,0 \mathrm{~km}^{2}\right)$. No segundo ano da implantação do monitoramento já foram observadas diferenças significativas na disponibilidade hídrica das duas bacias. A média da vazão específica de cada bacia não apresenta diferença significativa, devido aos elevados picos de vazão da bacia urbanizada, que compensam sua redução significativa nas vazões mínimas. Foram observadas, ainda, diferenças de 3 a 10 vezes entre as vazões terminais de estiagens máximas esperadas nas duas bacias, com vantagem para a bacia produtora em relação à urbanizada Palavras-chave: Vazão de base. Monitoramento de pequenas bacias. Conservação ambiental.

\section{Abstract}

This study presents the comparison of flowrates in two small watersheds to predict the impacts of urbanization scenarios over the Jardim stream basin, which reflects the occupation of the Cachoeira creek in the present. The study has been developed over two watersheds between the cities of Valinhos and Vinhedo, state of São Paulo, where the Jardim stream is used as water source $\left(23.5 \mathrm{~km}^{2}\right)$ and the Cachoeira creek is predominantly urban $\left(15.0 \mathrm{~km}^{2}\right)$. In the second year of the monitoring program it was clear that there were significant differences in the water availability between those watersheds. The mean specific flowrate does not present significant difference, due to the highly elevated flow peaks in the urban watershed, which compensate its lower minimum flowrates on average. In addition, it has been found that there are differences ranging from 3 to 10 times between the ending flowrates for an expected dry period to both streams, with the higher flow rates found in the water supplier watershed over the urban watershed. Keywords: Baseflow. Small watershed monitoring. Environmental conservation 


\section{INTRODUÇÃO}

A hidrologia básica define pequenas bacias como aquelas em que não ocorre amortecimento significativo da propagação do escoamento de água ao longo do seu canal principal, e a chuva acontece aproximadamente constante ao longo de sua duração. A melhor qualidade da água nas pequenas bacias periurbanas, por sua vez, favorece a captação de água bruta para o abastecimento público. Pequenas bacias, no entanto, de maneira mais frequente, não dispõem de séries fluviométricas históricas, essenciais para uma avaliação apropriada do comportamento da oferta hídrica do sistema. Dois problemas frequentemente decorrentes da falta de conhecimento mais apurado do comportamento da oferta hídrica em captações são 1) o superdimensionamento das estações elevatórias e de tratamento e 2) a alta frequência de interrupções para a manutenção dos equipamentos, devido à falta de referência para identificar a sobrecarga do sistema ao longo da vida útil. Cordery e Cloke (1992) demonstram que estações de tratamento de água projetadas a partir de séries fluviométricas recuperam cinco vezes os investimentos feitos na implantação e operação de estações fluviométricas. Por outro lado, os apelos sociais no sentido de obter maior conhecimento e preservação do recurso hídrico e, ainda, a necessidade de redução dos custos operacionais no setor oferecem campo fértil para a informatização do saneamento. No Brasil a Rede Hidrometeorológica Nacional (ANA, 2009) possui 4.259 estações fluviométricas, das quais 3.577 estão ativas. A rede nacional, no entanto, ainda é pouco aproveitada pelo setor de saneamento, pelo fato de sua distribuição ter sido definida em torno da geração hidrelétrica (SILVEIRA E TUCCI, 1998).

As estratégias de operação e implantação de estações de captação de água para abastecimento são determinadas pelas próprias prestadoras, sujeitas à vazão outorgada pelo sistema de gerenciamento de recursos hídricos. Neste trabalho, descreve-se o caso do projeto de monitoramento de córregos em Valinhos e Vinhedo, SP, realizado pelo Laboratório de Hidrologia da Unicamp, Departamento de Águas e Esgoto de Valinhos (DAEV) e Departamento de Água e Energia Elétrica do estado de São Paulo (DAEE). 0 objetivo deste trabalho é avaliar de forma indireta os impactos da urbanização de uma bacia hidrográfica a partir da comparação do comportamento hidrológico do ribeirão Jardim em relação ao comportamento do curso d'água principal de uma bacia hidrográfica circunvizinha em processo mais adiantado de urbanização, qual seja o córrego da Cachoeira.

\section{2 ÁREA DE ESTUDO}

A área de estudo localiza-se sobre os municípios de Valinhos (101 mil habitantes) e de Vinhedo (70 mil habitantes), no estado de São Paulo. A área é constituída pelas bacias hidrográficas do ribeirão Jardim e do córrego da $\mathrm{Ca}-$ choeira, onde se encontram, respectivamente, as represas Moinho Velho e João Antunes dos Santos, do Departamento de Água e Esgoto de Valinhos (DAEV), e o Parque João Gasparini de Vinhedo (Figura 1).

A bacia da seção fluviométrica do ribeirão Jardim possui $23,5 \mathrm{~km}^{2}$. A bacia da seção fluviométrica do córrego Cachoeira possui $15,0 \mathrm{~km}^{2}$. A precipitação média anual na região é de $1.338 \mathrm{~mm}$. 0 solo em toda a área é constituído de argissolos. Portanto, ambas as bacias apresentam características de clima e solo equivalentes. Por outro lado, as ocupações das áreas de ambas as bacias hidrográficas possuem características distintas. Ao passo que a área da bacia hidrográfica do ribeirão Jardim possui uma proporção de $18 \%$ de vegetação nativa e reflorestamento, a bacia do córrego da Cachoeira apresenta $40 \%$ de área urbana, pertencente ao município de Vinhedo. 

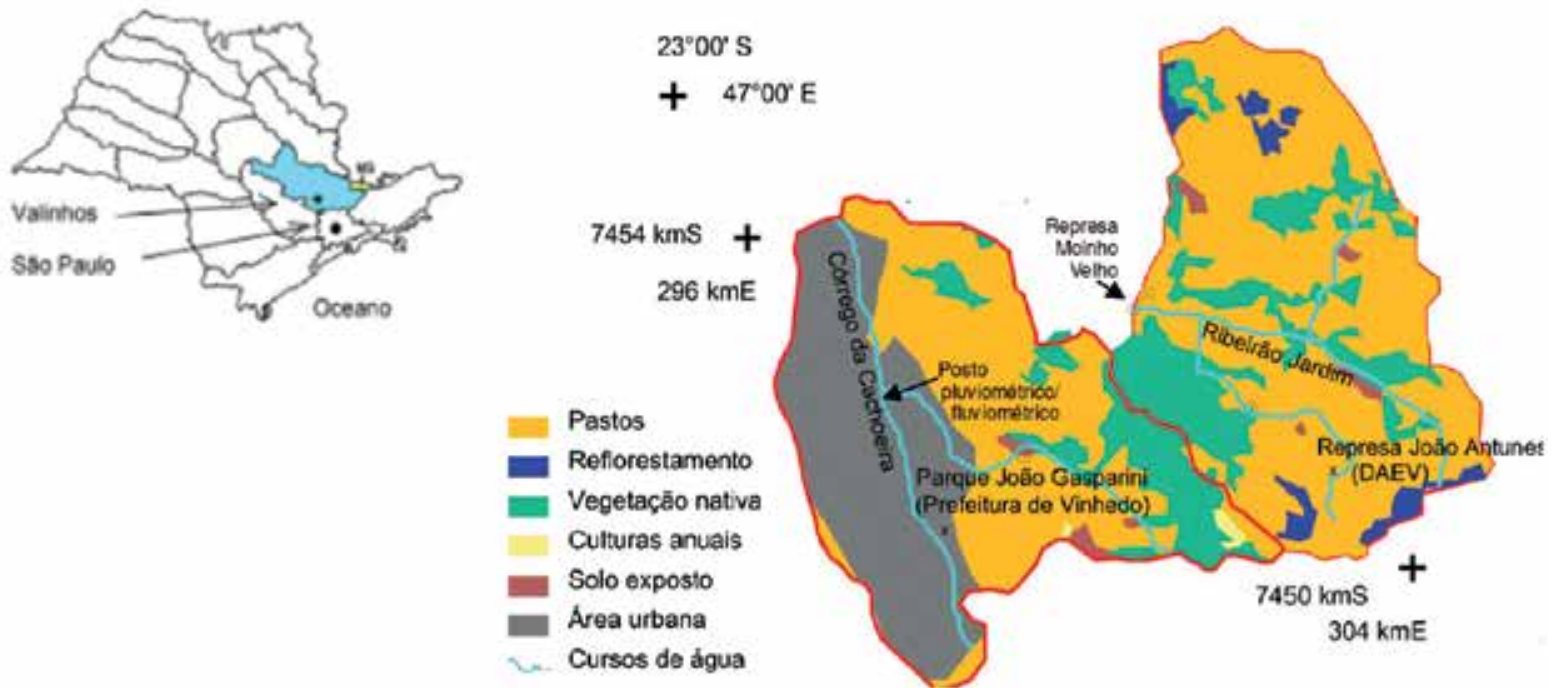

Figura 1 - Localização da área de estudo

\section{MATERIAL E MÉTODO}

A bacia do ribeirão Jardim possui um pluviômetro, localizado na área administrativa da represa João Antunes dos Santos, às coordenadas $23,0325^{\circ} \mathrm{S}$ e $46,9665^{\circ} \mathrm{W}$, em funcionamento desde 20/02/14 (Figura 2a). O pluviógrafo é do tipo basculante, realiza leituras de $0,1 \mathrm{~mm}$ e está programado com resolução temporal de $10 \mathrm{~min}$. 0 posto dispõe de leituras manuais por proveta em pluviômetro Helmann para dupla verificação das leituras do pluviógrafo. Na bacia do córrego da Cachoeira são encontrados dois pluviógrafos, sendo um localizado no canal do córrego, coordenadas $23.0117^{\circ} \mathrm{Se} 46.9841^{\circ} \mathrm{W}$, junto ao posto fluviométrico (Figura 2b), e o segundo no parque João
Gasparini, coordenadas $23,0322^{\circ} \mathrm{S}$ e $46,969^{\circ} \mathrm{W}$, em funcionamento desde 18/09/15 (Figura 2c).

Os postos encontram-se a no máximo $3,0 \mathrm{~km}$ do posto pluviométrico E3-017 (coordenadas $23,033^{\circ} \mathrm{S}$ e $46,967^{\circ} \mathrm{W}$ ), mantido pelo DAEE, cuja série é compreendida de 1936 a 1995. Devido à localização suficientemente próxima entre os postos para desprezar a variabilidade espacial das precipitações e ao curto comprimento das séries estudadas, o posto pluviométrico E3-017 é adotado como referência histórica dos postos monitorados. Portanto as séries estudadas, permitem a análise do comportamento das precipitações mensais em relação às médias mensais históricas. A análise dos períodos de estiagem, por sua vez, foi realizada a partir das precipitações diárias.

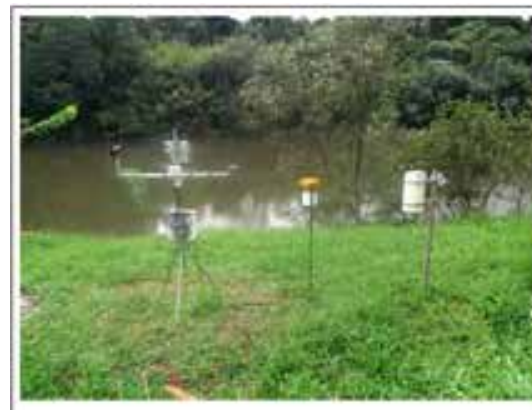

a) Posto da represa JAS

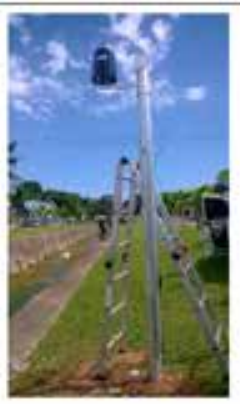

b) Posto do córrego da Cachoeira

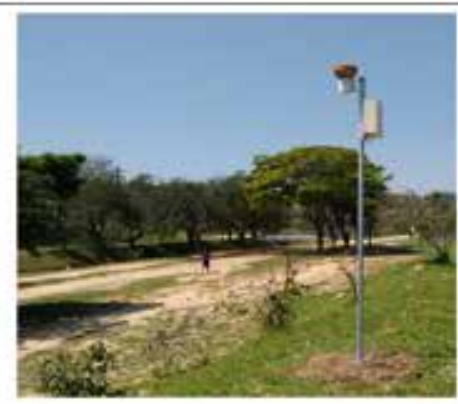

c) Posto do parque Joào Gasparini

Figura 2 - Postos pluviométricos represa João Antunes dos Santos (JAS), córrego da Cachoeira e parque João Gasparini. 
A seção fluviométrica do ribeirão Jardim encontra-se em trecho retificado com declividade longitudinal constante e igual a $10,0 \mathrm{~m} / \mathrm{km}$. A profundidade do canal é de 2,0 $\mathrm{m}$ e a seção trapezoidal tem base $3,5 \mathrm{~m}$ e taludes 1,4:1. Não há remanso a jusante da seção e o vertedor opera livre. Devido às características da seção transversal do canal da estação, a seção foi equipada com um vertedor metálico de parede fina com seção composta instalado no fundo do canal e um limnígrafo de pressão (Figura 3). A seção encontra-se equipada e produzindo leituras a partir de $22 / 05 / 15$, às coordenadas $22.9987^{\circ} \mathrm{S}$ e $46.9617^{\circ} \mathrm{W}$. O local da seção foi definido a $50 \mathrm{~m}$ da barragem, onde o escoamento é encontrado fora da zona de perdas de carga localizada devido ao transbordamento do reservatório. 0 limnígrafo da seção encontra-se 3,0 m a montante do vertedor metálico, de modo a registrar a carga hidráulica de montante do vertedor (y) e evitar interferências na relação cota-descarga do vertedor. A lei do vertedor, por sua vez, é obtida somando-se a vazão por meio de cada setor do vertedor, cuja geometria é caracterizada de forma específica na literatura de Engenharia (PRONI, 1990). Sendo assim, tem-se a combinação de vertedores triangulares (Thomson) e vertedores de Bazin (fórmula de Francis), resultando na seção utilizada.
A Equação 1 expressa o comportamento da seção composta, sendo $Q$ a vazão de escoamento $\left(\mathrm{m}^{3} / \mathrm{s}\right)$, $K$ uma constante multiplicadora obtida em função das propriedades geométricas da seção do vertedor à lâmina y (-) e y a lâmina de escoamento a montante do vertedor $(\mathrm{m})$. A demonstração da Equação 1 foge do escopo desta nota técnica. O esboço geométrico do vertedor consta na Figura 3b.

$Q=\sum_{i=1}^{5} K_{i}\left[\left(y-H_{0_{i}}\right)^{m_{i}}\right]$

Equação 1

Cada termo $i$ da Equação 1 é avaliado apenas na condição de $y>H_{0}$, sendo $H_{0}$ a elevação do vertedor em relação ao fundo do canal (m). Os parâmetros $K$, $H_{0}$ e m encontram-se listados na Tabela 1. Esta seção monitora as vazões da bacia do ribeirão Jardim, a jusante da estação de represa Moinho Velho do DAEV.

Tabela 1 - Valores dos parâmetros geométricos e hidráulicos do vertedor do posto fluviométrico do ribeirão Jardim

\begin{tabular}{|c|c|c|c|}
\hline $\boldsymbol{i}$ & $\boldsymbol{H}_{\mathbf{0}}$ & $\boldsymbol{K}$ & $\boldsymbol{m}$ \\
\hline & $\mathbf{( m )}$ & $\mathbf{( - )}$ & $\mathbf{( - )}$ \\
\hline 1 & 0,00 & 2,40 & 2,5 \\
\hline 3 & 0,20 & $-2,40$ & 2,5 \\
\hline 4 & 0,20 & 3,64 & 1,5 \\
\hline 5 & 0,50 & 4,61 & 1,5 \\
\hline
\end{tabular}

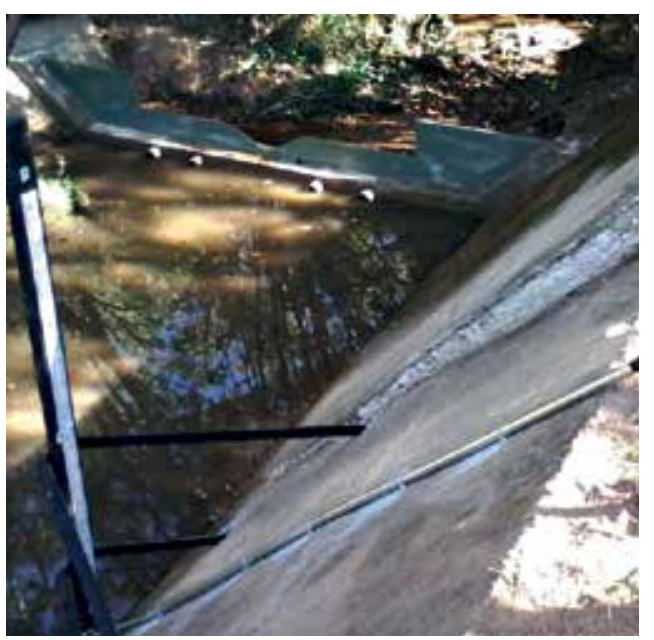

(a)

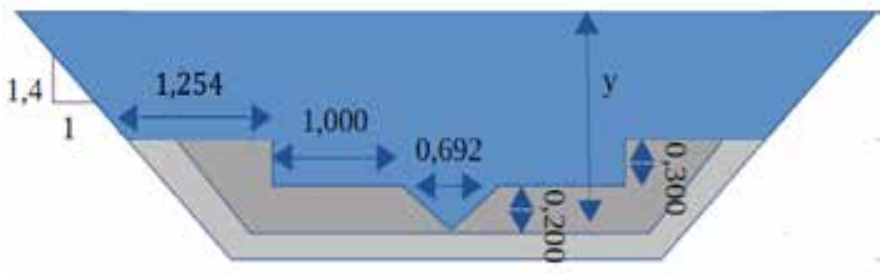

(b)

Figura 3 - Posto fluviométrico do ribeirão Jardim. a) Foto com vista para jusante. Abaixo na foto, régua limnimétrica (vertical) e limnígrafo (parede). Acima, vertedor de parede fina com seção composta. b) Esboço geométrico do vertedor (cotas em metros) 
O posto fluviométrico do córrego da Cachoeira encontra-se às coordenadas $23.0117^{\circ} \mathrm{S}$ e $46.9841^{\circ}$ $\mathrm{W}$, instalado à margem de trecho retificado, com paredes e fundo revestidos com concreto. A seção encontra-se equipada e produzindo registros desde 30/01/14. O canal possui seção transversal retangular com largura $B=8,4 \mathrm{~m}$, altura de $2,95 \mathrm{~m}$ e declividade longitudinal, $\mathrm{S}_{0}=0,0064$. $O$ número de Manning foi estimado por intermédio de medição de vazão em regime permanente por flutuadores por $n=0,019+0,001$. O posto encontra-se equipado com limnígrafo de fundo e régua limnimétrica na parede do canal, conforme ilustrado na Figura 4. A relação cota-descarga para o canal em regime permanente corresponde à aplicação da fórmula de Manning no canal. Negligenciando-se a aceleração advectiva, em vista de o canal ser prismático e a aceleração local, pois a variação da velocidade ao longo do tempo é desprezível devido à duração da onda, tem-se a vazão na seção, Q ( $\left.\mathrm{m}^{3} / \mathrm{s}\right)$ dada pela fórmula de Jones (1915), conforme a Equação 2.

$$
Q=Q_{0} \quad 1-{\frac{1}{S_{0} c}}_{\frac{\partial y}{\partial t}}{ }^{\frac{1}{2}}
$$

Equação 2

sendo Q r a vazão de referência dada pelo regime permanente uniforme $\left(\mathrm{m}^{3} / \mathrm{s}\right)$ correspondente à lâmina de escoamento $y(\mathrm{~m})$. $\mathrm{O}$ termo celeridade $\mathrm{c}$ $(\mathrm{m} / \mathrm{s})$ é dado por $c=b V$, sendo $b$ a constante de proporcionalidade entre a velocidade média na seção $(\mathrm{m} / \mathrm{s})$ e a celeridade, $b=5 / 3(-)$. 0 gradiente $\partial y / \partial t$ é aproximado pela diferença de lâmina d'água no limnímetro dividido pelo intervalo de tempo entre as respectivas leituras limnimétricas.

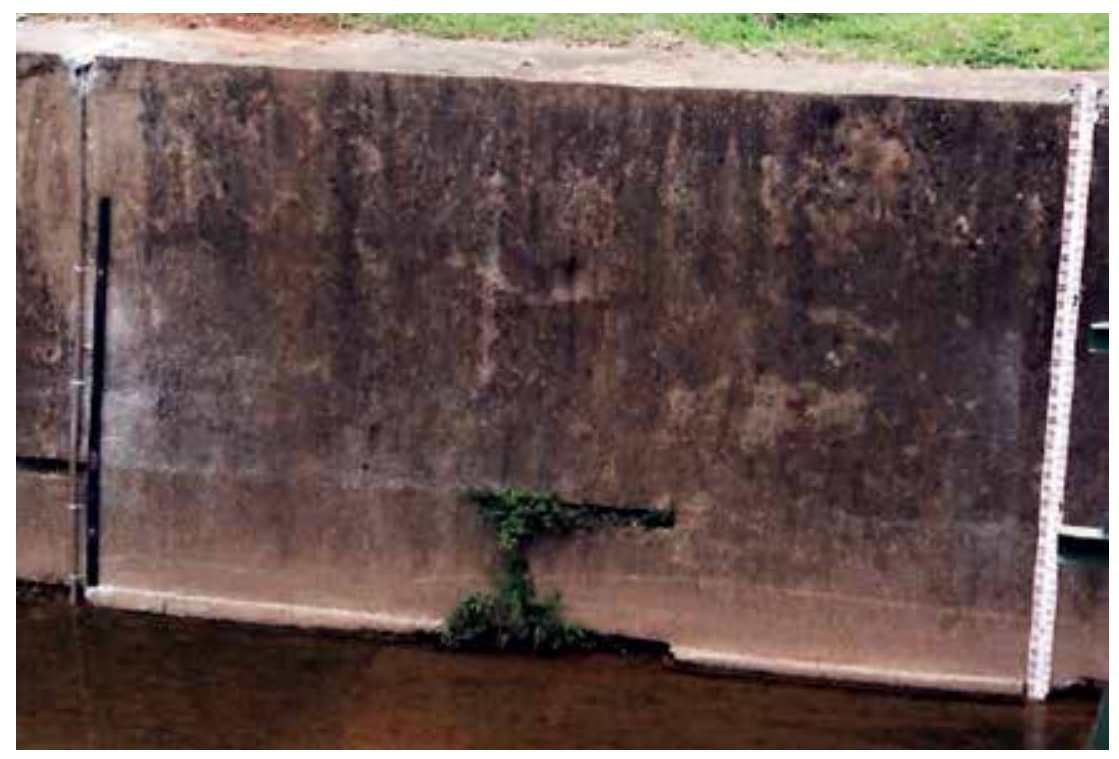

Figura 4 - Posto fluviométrico do córrego da Cachoeira. Sentido do escoamento da direita para a esquerda da figura. À direita, régua limnimétrica. À esquerda, limnígrafo.

O critério mais utilizado para a segmentação de períodos de recessão em análises de séries de vazão mínima é adotar início e término do período de recessão de vazão mínima a cada par consecutivo de máxima e mínima, respectivamente (e.g. VOGEL E KROLL, 1992; STOELZLE et al.,2013). Por outro lado, segundo Tallaksen (1995), os períodos de recessão da vazão mínima são definidos com menos interferências durante estiagens maiores que sete dias. A identificação de períodos de recessão da vazão mínima compreendido pelos respectivos períodos de estiagem permite 
a triagem de recessões de maneira mais apropriada, diretamente relacionada às condições de ausência de chuvas e às propriedades hidráulicas do solo. A curva de recessão é determinada a partir da equação da continuidade para a recessão do armazenamento em função da vazão efluente do aquífero, $d S / d t=-Q(t)$ (e.g. BEAR, 1972). Logo, o coeficiente de recessão é obtido pela expressão:

$k=-\frac{1}{t-t_{0}} \ln \frac{Q}{Q_{0}}$

Equação 3

sendo $S=k Q$ a lei de armazenamento no aquífero, conforme a lei de Darcy; $t-t_{0}$ o intervalo de tempo em dias entre as leituras de vazão mínima diária, $Q$ e $Q_{0}$, e $k$ é o coeficiente de recessão em $\mathrm{dia}^{-1}$.

\section{RESULTADOS E DISCUSSÕES}

O período de monitoramento analisado para o córrego da Cachoeira corresponde ao início do monitoramento em 20/02/14 ao final do ano de 2015. O período de monitoramento analisado para o ribeirão Jardim compreende do início em 22/05/15 ao final do ano de 2015. Existem quatro períodos de interrupções no monitoramento no ribeirão Jardim que não foram levados em conta para a obtenção das curvas de recessão, entre 15/07 e 06/08, 14/08 e 20/08, 07/11 e 26/11, 15/12 e 18/12. O monitoramento do córrego da Cachoeira possui dois períodos de interrupção, entre 19/06/14 a 02/07/14 e entre 16/05/15 e 01/10/15.

\subsection{Vazões mensais}

A vazão específica média mensal $\left(\mathrm{m}^{3} / \mathrm{s} . \mathrm{km}^{2}\right)$ apresenta valores próximos entre as bacias Jardim e Cachoeira, a despeito das ocupações diferenciadas (Figura 5). Essa proximidade entre as vazões médias deve-se aos elevados valores das vazões máximas na bacia do Cachoeira devido à urbanização, que eleva a vazão média a despeito de reduzir a vazão mínima. Por outro lado, a vazão mínima no ribeirão Jardim aproxima-se mais do valor médio, devido à menor flutuação das vazões na bacia. 0 desvio padrão entre as máximas e as mínimas em relação à vazão média mensal no ribeirão Jardim é observado em $0,0044 \mathrm{~m}^{3} / \mathrm{s} . \mathrm{km}^{2}$, que representa um desvio quarenta vezes inferior ao obtido no córrego da Cachoeira, que é 0,203 m³/s. $\mathrm{km}^{2}, 45$ vezes superior ao ribeirão Jardim. As flutuações das vazões máximas em relação às vazões médias correspondem a coeficientes de correlação $60 \%$ e $37 \%$, respectivamente para o ribeirão Jardim e o córrego da Cachoeira. a)

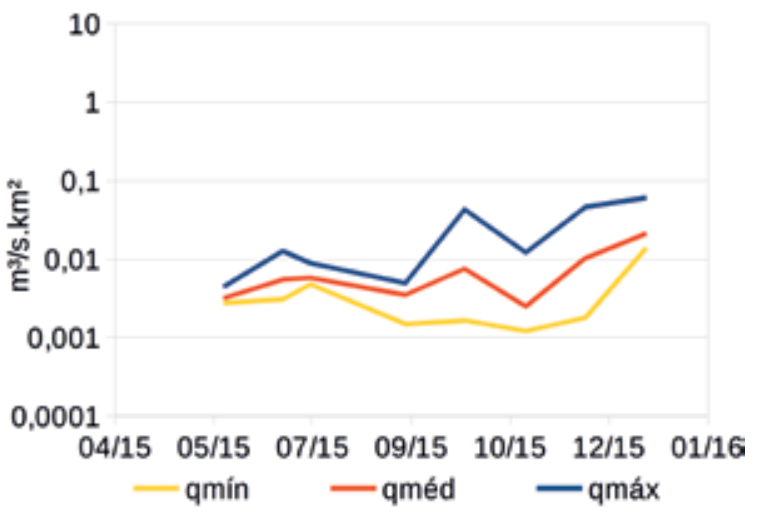

b)

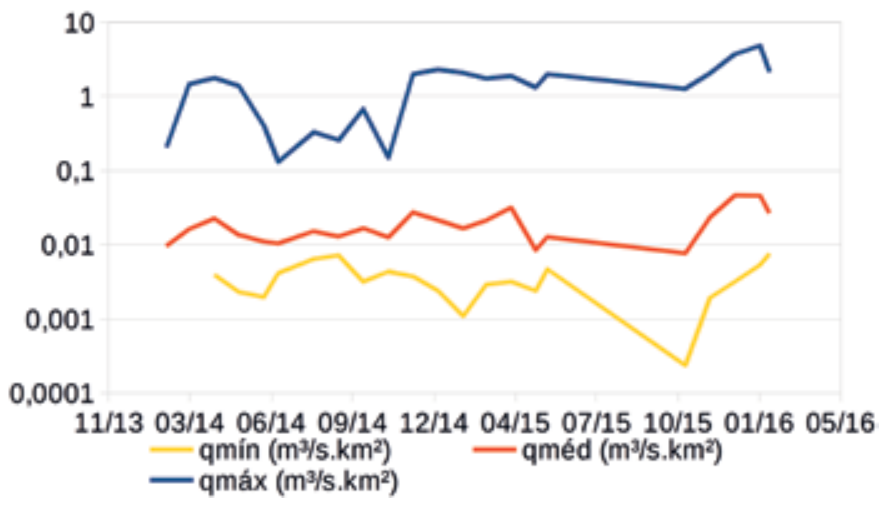

Figura 5 - Série de vazões mínimas, médias e máximas a) no ribeirão Jardim e b) no córrego da Cachoeira. 
Os resultados demonstram que as áreas impermeabilizadas da bacia produzem maiores volumes e maiores velocidades de escoamento, as quais implicam diretamente em maiores vazões máximas. Por outro lado, a área urbana, que consiste em áreas de solos compactados e pavimentados, reduz a recarga das águas subterrâneas, as quais estabelecem as vazões mínimas.

\subsection{Vazões diárias}

$\mathrm{Na}$ Figura 6 observa-se a flutuação dos coeficientes de recessão linear, $k$, obtidos em ambos os postos. A flutuação e o valor médio do coeficiente de recessão no posto do ribeirão Jardim $\left(k=0,09 \mathrm{dia}^{-1}\right)$ observados estão levemente abaixo daqueles observados no posto da Cachoeira $\left(k=0,22 \mathrm{dia}^{-1}\right)$. Estiagens superiores a sete dias filtram o número de períodos de recessão para o posto Jardim e o posto Cachoeira respectivamente para 4 e 11 períodos, cujos coeficientes de recessão, k, são avaliados com 0,19 $\mathrm{dia}^{-1}$ e 0,26 dia $^{-1}$ respectivamente.

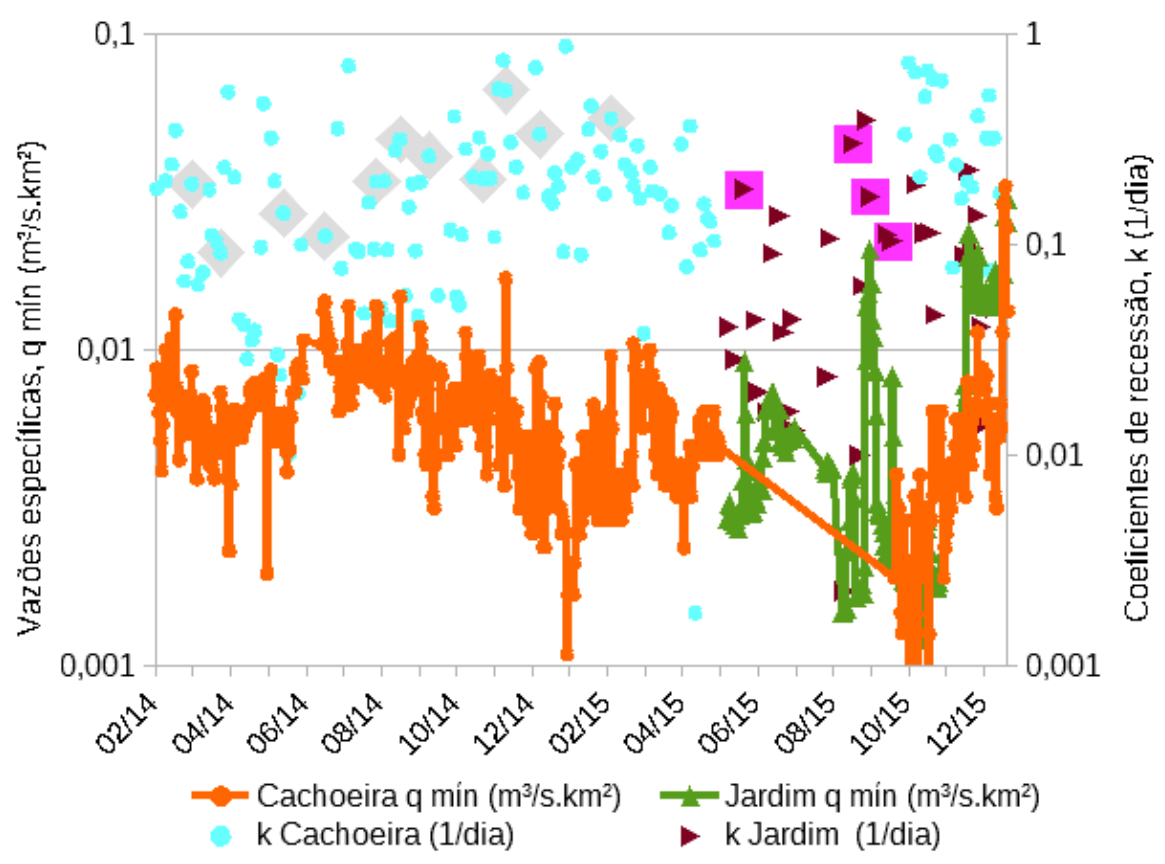

Figura 6 - Coeficientes de recessão linear das vazões mínimas diárias no ribeirão Jardim e no córrego da Cachoeira. Valores de coeficientes de recessão médios independentemente das precipitações, indicados pelos pontos azuis (Cachoeira) e marsala (Jardim). Coeficientes de recessão médios para estiagens superiores a sete dias, losangos cinzas (Cachoeira) e quadrados magenta (Jardim).

As estimativas de coeficiente de recessão permitem que sejam estudados cenários de vazão mínima ao final de um período de estiagem. Na Figura 7, apresentam-se as quedas percentuais de vazão mínima entre o início e o fim de acordo com diferentes períodos de estiagem, no ribeirão Jardim e no córrego da Cachoeira, estimadas a partir da média dos respectivos coeficientes de recessão superiores a sete dias. 


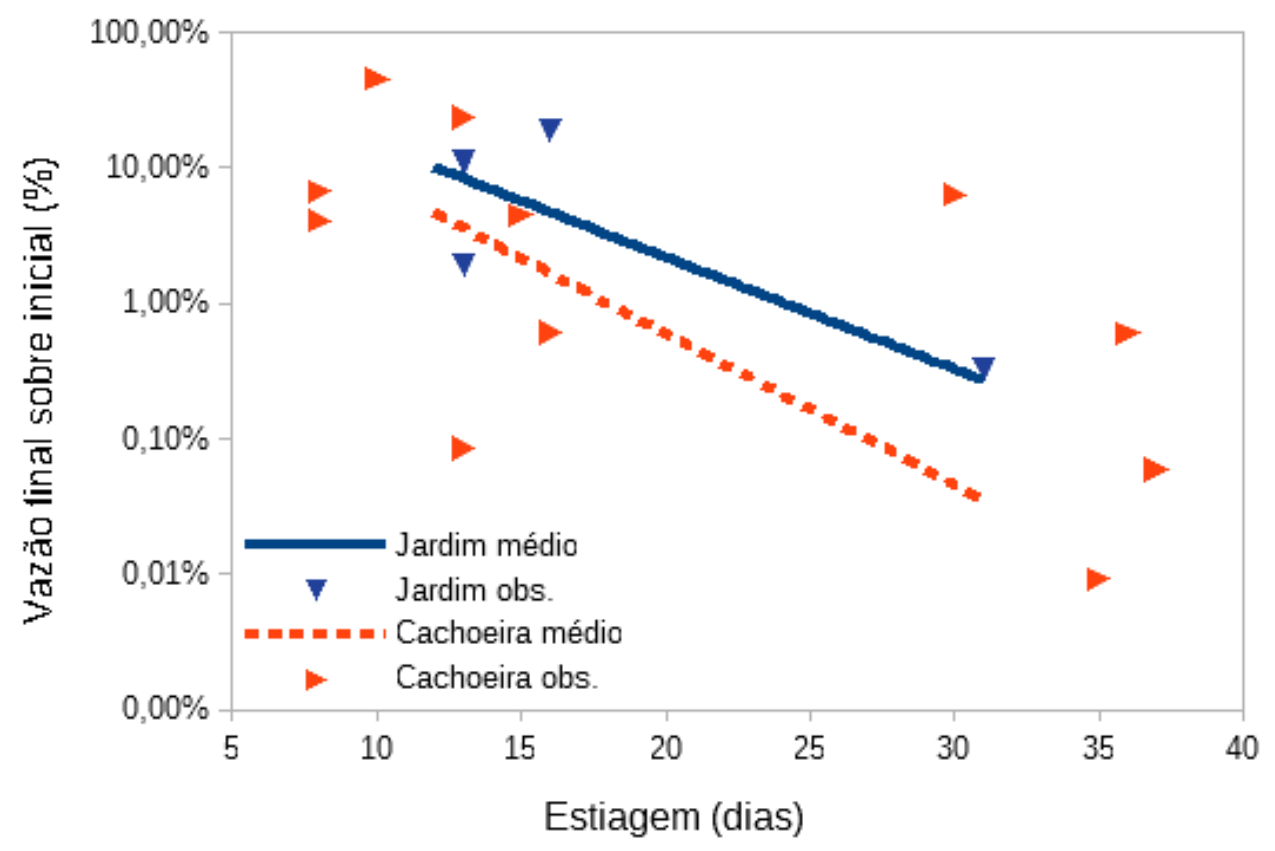

Figura 7 - Porcentagem da vazão final sobre a vazão inicial em períodos de estiagem para o ribeirão Jardim e o córrego da Cachoeira. Linhas contínuas indicam quedas estimadas a partir da média dos respectivos coeficientes de recessão.

Pontos em triângulos indicam (para baixo) as quedas observadas no ribeirão Jardim e (para a direita) no córrego da Cachoeira para estiagens superiores a sete dias.

Observa-se na Figura 7 que as vazões mínimas do ribeirão Jardim possuem quedas sistematicamente inferiores às do córrego Cachoeira. Aos doze primeiros dias de estiagem, a vazão no ribeirão Jardim cai a $10 \%$, enquanto no córrego da Cachoeira a vazão cai a 3,2\% da inicial, que corresponde a uma vazão específica três vezes superior no ribeirão Jardim. Aos 19 dias de estiagem, a vazão no ribeirão Jardim cai a $2,7 \%$, mantendo ainda uma vazão específica seis vezes superior à do córrego da Cachoeira. Assim, as vazões no ribeirão Jardim são relativamente mais preservadas ao longo do tempo, com razões entre as vazões neste e naquele posto variando entre os cenários de estiagem, entre 3 e 10 vezes as vazões da bacia urbanizada (Cachoeira).

\section{CONCLUSÕES}

Durante o período estudado, de fevereiro de 2014 a dezembro de 2015, a vazão mínima das bacias do ribeirão Jardim e do córrego da Cachoeira ob- servou padrões significativamente diferenciados em relação à dispersão dos valores em torno da média. Enquanto as vazões específicas médias de ambas as bacias corresponderam a $0,0038 \mathrm{~m}^{3} / \mathrm{s}$. $\mathrm{km}^{2}$ e $0,0033 \mathrm{~m}^{3} / \mathrm{s} . \mathrm{km}^{2}$ respectivamente, o desvio médio entre as máximas e as mínimas em relação à vazão média mensal respondeu com 0,0044 m³ $/ \mathrm{s}$. $\mathrm{km}^{2}$ e $0,203 \mathrm{~m}^{3} / \mathrm{s} . \mathrm{km}^{2}$. Portanto, desvios aproximadamente 50 vezes superiores foram encontrados no córrego da Cachoeira. O estudo da curva de recessão entre as bacias demonstrou, ainda, que o coeficiente de recessão da bacia do córrego da Cachoeira (0,29 dia-1) é $50 \%$ superior ao da bacia do ribeirão Jardim (0,19 dia-1). Isso significa que, durante estiagens, o ribeirão Jardim possui vazões finais entre 3 a 10 vezes superiores às apresentadas no córrego da Cachoeira. Os resultados obtidos neste período inicial do monitoramento demonstram algumas das diferenças de comportamento na disponibilidade hídrica causadas por diferentes configurações de ocupações do solo. 


\section{REFERÊNCIAS BIBLIOGRÁFICAS}

ANA, A.N. de Á., 2009. Sistema de Monitoramento Hidrológico.

Disponível em: http://mapas-hidro.ana.gov.br/Usuario/mapa.aspx

BEAR, J., 1972. Dynamics of fluids in porous media. American

Elsevier, New York.

CORDERY, I., CLOKE, P.S., 1992. Economics of Streamflow Data Collection. Water Int. 17, 28-32. doi:10.1080/02508069208686125

JONES, B. E., 1915. A method of correcting river discharge for a changing stage, U.S. Geological Survey Water Supply Paper, 375-E, pp117-130.
PROGRAMA NACIONAL DE IRRIGAÇÃO (PRONI). Estruturas de medição de vazão para pequenos cursos d'água São Paulo. PRONI /FCTH, 1990. v1.

SILVEIRA, G.L., TUCCI, C.E.M., 1998. Quantificação de vazão em pequenas bacias sem dados. Rev. Bras. Recur. Hídricos, 3, 111-131.

STOELZLE, M., STAHL, K., WEILER, M., 2013. Are streamflow recession characteristics really characteristic? Hydrol. Earth Syst. Sci. 17, 817-828. doi:10.5194/hess-17-817-2013

TALLAKSEN, L.M., 1995. A review of baseflow recession analysis. J. Hydrol. 165, 349-370. doi:10.1016/0022-1694(94)02540-R

VOGEL, R.M., KROLL, C.N., 1992. Regional geohydrologic-geomorphic relationships for the estimation of low-flow statistics. Water Resour. Res. 28, 2451-2458. doi:10.1029/92WR01007 